PLEASE NOTE:

This is the author's version of the manuscript accepted for publication in [European Journal of Developmental Psychology]. Changes resulting from the publishing process, namely editing, corrections, final formatting for printed or online publication, and other modifications resulting from quality control procedures, may have been subsequently added.

The published version can be found in: Martins, C., Mateus, V., Osório, A., Martins, E. C., Soares, I. (2014). Joint attention with the mother and the father at 10 months of age. European Journal of Developmental Psychology, 11, 319-330. doi: 10.1080/17405629.2013.821945 


\section{Joint attention with the Mother and the Father at 10 months of age}

\section{Abstract}

Joint attention capabilities were assessed in 52 10-month-olds observed independently with their mothers and fathers in a semi-structured toy-play condition. Mothers and fathers were indistinguishable in terms of total number of behaviors aimed at engaging their infant in joint attention. However, infants responded more to mothers' bids for attention than to fathers' bids. Contrastingly, infants tended to display more initiating joint attention behaviors while interacting with their fathers. Although parents did not differ in terms of sensitivity, fathers were less intrusive than mothers. Results are discussed in terms of the specificities of mother-infant and father-infant interaction and how the paternal role should be highlighted in the case of infant's joint attention development.

Keywords: joint attention; infancy; mothers; fathers 


\section{Introduction}

In the second half of the first year of life, infants become capable of engaging in triadic interactions in which they share attention with another person regarding an object or event, an ability commonly referred to as joint attention (Bakeman \& Adamson, 1984). This capacity is considered a critical milestone in early child development, which is related to language acquisition (e.g., Carpenter, Nagell, \& Tomasello, 1998; Vaughan Van Hecke et al., 2007), later theory of mind (e.g., Nelson, Adamson, \& Bakeman, 2008), as well as subsequent behavioral and social outcomes, such as social competence and prosocial behaviors (e.g., Mundy \& Sigman, 2006; Sheinkopf, Mundy, Claussen, \& Willoughby, 2004; Vaughan Van Hecke et al., 2007). In addition, impairments in joint attention are considered early markers of risk for developmental disorders such as autism (e.g., Dawson et al., 2004; Toth, Munson, Meltzoff, \& Dawson, 2006).

Joint attention skills are frequently assessed in terms of infants' ability (i) to respond to a social partner's bids to share a common attentional focus, for example by following other's gaze or pointing gesture, and (ii) to spontaneously initiate joint attention by looking at, pointing, offering, or showing objects to the social partner (Mundy et al., 2007; Osório, Martins, Meins, Martins, \& Soares, 2011). To study these behaviors, infant-tester paradigms have been developed (e.g., Mundy et al., 2007; Sheinkopf et al., 2004) under the assumption that those might maximize individual differences in infants' joint attentional abilities (Vaughan et al., 2003). However, infant-caregiver interaction paradigms have also been developed and used in the past decade (Gaffan, Martins, Healy, \& Murray, 2010; Martins, 2003; Meins et al., 2011; Osório et al., 2011). Assessing joint attention skills in interaction with a significant social partner (e.g., the mother) may provide important data on infant's optimal capacity to engage in triadic interactions. Moreover, motherinfant paradigms address the study of the contributions of the relational context to infants' individual differences in joint attention (e.g., Gaffan et al., 2010; Mundy \& Sigman, 2006; Osório et al., 2011). Indeed, previous investigations have highlighted how mothers may "scaffold” infants' 
early joint attention behaviors, for instance, by showing, talking about, or performing actions on an object (e.g., Bakeman \& Adamson, 1984; Gaffan et al., 2010; Vaughan et al., 2003). Furthermore, maternal interactive characteristics, such as sensitivity and the ability to follow infant's focus of attention, have been found to foster the developing capacity to engage in triadic interactions (e.g., Hobson, Patrick, Crandell, Pérez, \& Lee, 2004; Legerstee, Markova, \& Fisher, 2007).

Despite the growing body of knowledge highlighting the maternal contributions to infant joint attention development, there are few studies focusing on father-infant dyads. For instance, Hsu's investigation (1996) of paternal contributions to joint attention occurring in mother-father-infant triads revealed that mothers and fathers seemed to play complementary roles concerning the promotion of joint attention engagement. Whereas mothers provided more cues and suggestions to facilitate infants' performance, fathers were more likely to decide on the task's direction by planning it and making decisions. On the other hand, Rutherford and Przednowek (2012) compared maternal and paternal interactiveness with their infant, a set of behaviours whose description is very close to that of joint attention ("the sharing of the toy, joint contact with the toy, and mutual eye contact”, p. 372). Their results showed that mothers and fathers employed the same amount of interactiveness with their infants. Of note, however, is the fact that their study used an betweensubjects design, which might preclude firm conclusions on the similarities or differences between mothers and fathers controlling for the effect of the infant with which they are interacting.

Over the past decades, the increased participation of women in the labor force and the emergence of different patterns of family organization have highlighted the importance of exploring fathers’ roles in children's lives (Cabrera, Tamis-LeMonda, Bradley, Hofferth, \& Lamb, 2000). Specifically, fathers seem to be likely candidates to influence the development of joint attention since they have already been proven as determinant to several related competences. Recent studies showed how high quality father-infant interactions may impact upon infants' cognitive development (Cabrera, Shannon, \& Tamis-LeMonda, 2007; Lamb \& Lewis, 2010), linguistic outcomes 
(Pancsofar, Vernon-Feagans, \& The Family Life Project Investigators, 2010; Tamis-LeMonda, Shannon, Cabrera, \& Lamb, 2004), and later social competence (Berlin, Cassidy, \& Appleyard, 2010; Cabrera et al., 2000; Lamb, 2010). In addition, researchers have also been focused on paternal contribution to infants' emotion regulation (Flanders et al., 2010) and attachment security (Grossmann, Grossmann, Kindler, \& Zimmermann, 2008). For instance, an investigation with Portuguese families revealed that fathers who were actively involved in and shared child-related activities, such as nurturance and leisure time, in equal proportion with their wives had children with higher attachment security scores (Monteiro et al., 2010).

Previous studies suggest that mothers and fathers tend to present similar - rather than different - behaviors when interacting with their young children (e.g., Belsky, 1979; Cabrera et al., 2007; Lamb \& Tamis-LeMonda, 2004; Lamb \& Lewis, 2010). Just like mothers, fathers adjust their behavior when interacting with their infants, namely by performing their actions repeatedly, more slowly, and in a more interactive way, than when interacting with other adults (Rutherford \& Przednowek, 2012). Furthermore, fathers, like mothers, can be supportive, sensitive, and cognitively stimulating to their children (Cabrera et al., 2007; Tamis-LeMonda et al., 2004). Thus, if supportive mothering has been associated to children's cognitive development, fathers' contribution seems to be equally important for their children's cognitive and emotional development especially at earlier ages (Cabrera et al., 2007). Nevertheless, research has also highlighted some differences between maternal and paternal interactive characteristics and contributions for their offspring development. For instance, Rutherford and Przednowek (2012) found that fathers displayed closer physical proximity and provided more opportunities for joint contact between their infant and a novel toy than did mothers. This is in line with some studies (see Lamb, 2010) stating that fathers are more prone to a kind of play characterized by close physical contact and that is highly vigorous (i.e., rough-and-tumble play). This play has particular arousing qualities, leading some to believe that father-infant interactions are especially prominent and 
impacting on child's development, even though fathers tend to spend less time with their children (Flanders et al., 2010; Lamb, 2010). Finally, mothers’ intrusiveness tends to exert greater influence on child outcomes than fathers' negative behaviours (Tamis-LeMonda et al., 2004). In the same line, Bigelow and colleagues’ (2010) study also indicates that an intrusive maternal interactive style limits infants' play activity, whereas positive mother-infant interaction sustains the dyad's engagement in joint attention episodes (Bigelow et al., 2010).

The contribution of fathers' behaviours to joint attention in infants, and how it can be distinguished from the impact of mothers' behaviours, is yet to be demonstrated. The current investigation aims at filling this gap by using a within subjects design to (i) explore the differences and commonalities in joint attention behaviors in 10-month-old infants observed with their mothers and with their fathers in independent sessions of semi-structured toy-play; (ii) relate those differences to maternal and paternal interactive style, in terms of sensitivity and non-intrusiveness, during a typical daily interaction, including routines (e.g., feeding) and playing. Two hypotheses are laid out. As suggested by previous research, we anticipate that a) both parents will exhibit similar patterns of behaviour during interaction with their children. Therefore, we predict no differences between mothers' and fathers' bids for joint attention in the semi-structured toy-play session. However, as mothers often play the role of primary caregiver during early years, spending more time interacting with their children, we hypothesize that b) infants will display higher levels of responding and initiating joint attention in interaction with their mothers than with their fathers. If any differences are to be found between mothers' and fathers' joint attention behaviours, maternal and paternal interactive styles will be compared in terms of their sensitivity and non-intrusiveness during daily routines interactions.

\section{Method}

\section{Participants}


Fifty-two infants (31 boys, 59.6\%) aged 9 to 11 months $(M=10.38, S D=.36)$, and their mothers and fathers, involved in a larger longitudinal study (Martins, Soares, Martins, Tereno, \& Osório, 2012; Mateus, Martins, Osório, Martins, \& Soares, 2012; Osório et al., 2011), were recruited from day childcare centers in a large city in the north of Portugal. Mothers' age ranged from 25 to 45 years $(M=33.45, S D=4.76)$, whereas fathers were aged 21 to 44 years $(M=33.68$, $S D=4.60$ ). All infants were White, had Portuguese as their first language, and came from twoparent middle- to middle-upper socioeconomic households.

\section{Procedure}

Assessments of infant-mother and infant-father interactions were carried out, in independent sessions, in the families’ house. Each session lasted approximately 40 minutes, segmented in three different phases. In the first 20 minutes, parents were asked to carry out their normal routine that could involve feeding or bathing the infant or any other activity, so that the dyad would become accustomed with the researcher's presence. Then, mothers and fathers were asked to play with their babies as they would normally do using the infant's favorite toys, allowing for a 10-minute free play period. Finally, in the third phase, parents were presented with a shape shorter bucket and instructed to teach their infants how to play with the new toy - 10-minute semi-structured toy-play. Infants were initially observed in interaction with their mothers and within a maximum of two weeks after the first visit observations of infant-father dyads were conducted. The total procedure was video-recorded for subsequent coding.

\section{Instruments}

Joint Attention Behaviours. The 10-minute semi-structured toy-play (third phase) was coded for joint attention behaviours using a coding system focused on the infant's response to adult bids 
for joint attention and the occurrence of efforts to direct the adult's attention to a target (Martins, 2003; Osório et al., 2011).

The frequency of seven parental bids for joint attention behaviours was coded: engaging with contact (playfully touching the infant's body using the toy); animating a toy (expressive performance with the toy to entertain the infant); showing a toy (for example, raising the toy to infant's eye level); offering a toy; pointing (to indicate something with index finger extended); demonstrating an action (to perform specific actions on a toy with the intention of teaching the infant); and verbal directives (verbally encouraging the infant to perform an action on a toy). An overall score that reflected the total number of mothers' and fathers' bids for joint attention was computed.

Infant's response was coded when it occurred within six seconds (Mundy et al., 2003) of any of the parental behaviors presented above and received two possible codings: responds to joint attention (follows the mother's or father's action on the toy, and also alternates gaze between the toy and the mother/father); and ignores (coded when the infant does not look at the mother's or father's action at any point, revealing no interest in the toy). Responding to joint attention was scored as the proportion of instances of involvement in joint attention, divided by the total number of mothers' and fathers’ bids for joint attention.

Three types of infant behaviours were considered as attempts to initiate joint attention with the parent: animating a toy (moving the toy to get the mother's or father's attention); offering a toy (holding a toy in front of the parent); and pointing (index finger extended toward a target), which could be of communicative nature or non-communicative nature. All behaviours required the infant to look at the parent's face at some point during the action, except for pointing (which could be scored even in the absence of gaze alternation) The frequency of each type of infant's initiating joint attention behaviour was combined into an overall score. 
A randomly selected $20 \%$ of the interactions were coded by a second trained judge. Inter-rater reliability was calculated using Cohen’s kappa, which was adequate across all measures of joint attention (adult engages with contact $=.75$; adult animates toy $=.70$; adult shows $=.72$; adult offers $=.71$; adult points $=.71$; adult demonstrates $=.71$; adult gives verbal directives $=.71$; infant responding to joint attention $=.79$; infant initiating joint attention $=.73$ ).

Mothers' and Fathers' Interactive Style. Parents' interactive style was assessed during the initial 30 minutes of observation (first and second phases) using two scales of the Emotional Availability Scales $-3^{\text {rd }}$ edition (Biringen, Robinson, \& Emde, 1998) - sensitivity and nonintrusiveness scales. Sensitivity was evaluated on a 9-point scale reflecting parent's ability to interpret accurately infants' signs as well as provide prompt and appropriate responsiveness to them. On the other hand, non-intrusiveness, scored on a 5-point scale, refers to the extent to which a parent does not interfere with his child's autonomy and play. On both scales, higher ratings correspond to an optimal quality of parent-infant interaction. Mother-infant interactions were coded independently by four trained judges who were blind to other measures of the study. Then, $48 \%$ of the observations received double coding for reliability purposes. Inter-rater reliability, calculated using Intraclass Correlation Coefficient, revealed to be adequate across both measures of mothers' interactive style (sensitivity, $r_{i}=.88$, non-intrusiveness, $r_{i}=.77$ ). As for fathers, again $48 \%$ of the observations were double coded by two previously trained judges, blind to the other measures in the study, different from the set of four judges who coded the mothers. The obtained inter-rater reliability was adequate for sensitivity $\left(r_{i}=.95\right)$ and non-intrusiveness $\left(r_{i}=.87\right)$.

\section{Results}

Parents’ bids for attention variables were normally distributed and thus paired-samples t test were used. Contrastingly, infants' variables were markedly skewed leading to the use of the Wilcoxon signed-rank test. Likewise, due to the ordinal nature of parents' sensitivity and non- 
intrusiveness measures, the Wilcoxon signed-rank test was used. For all variables, means and standard deviations will be presented for the sake of interpretability (Howell, 2010).

All mothers and fathers (100\%) displayed at least one behaviour to engage their infants on joint attention. Thirty-two infants (61.5\%) presented at least one response to their mother's bids for joint attention and 26 infants (50.0\%) showed at least one instance of initiating joint attention. On the other hand, during infant-father interaction, 22 infants (42.3\%) responded to father's attempts to direct their attention, whereas half of the infants (50.0\%) showed efforts to share attention with fathers. Table 1 presents the comparisons between infant-mother and infant-father dyads in terms of joint attention behaviours.

Table 1 about here

Mothers and fathers were indistinguishable in terms of total number of attempts to engage their infants on joint attention, $t(51)=1.48, p=.145$. However, infants responded more to mothers' bids for joint attention than to fathers', $Z=-2.16, p=.031$. Contrastingly, initiating joint attention behaviours showed marginally significant differences, $Z=-1.90, p=.057$, with infants displaying the tendency to employ more efforts to direct their fathers' attention than their mothers'.

Regarding parents' interactive style, mothers and fathers presented similar levels of sensitivity, $Z=-1.05, p=.294$, but not of non-intrusiveness. Fathers were found to display a less intrusive style of interaction than mothers, $Z=-3.09, p=.002$ (see Table 2).

Table 2 about here

\section{Discussion}


In 1975, Michael Lamb called fathers the “forgotten contributors to child development”. His review paper was a wake-up call for researchers, some of whom have been focusing on the paternal contribution in their children's lives and healthy development. However, the joint attention field is yet to follow this tendency. To date, studies comparing and contrasting infant-mother and infantfather joint attention behaviours in dyadic contexts within the same families are still scarce. The present investigation, using a within-subjects design where the same infant was observed with his/her mother and father, aims to further contribute for the study of this issue.

The results of this study add important data to the joint attention literature. First, the resemblance in parents' attempts at engaging their infants on joint attention is noteworthy, and confirms our first hypothesis. This result is in line with other investigations focusing on how mothers and fathers interact with their infants in similar ways (e.g., Belsky, 1979; Cabrera et al., 2007; Lamb \& Lewis, 2010; Lamb \& Tamis-LeMonda, 2004) and expands such accounts to behaviours aimed at fostering joint attention.

Interestingly, however, despite the fact that mothers and fathers provided equal opportunities for infants to engage in joint attention, infants displayed more responding to joint attention to maternal than paternal bids, but tended to exhibit more initiating joint attention during interaction with their fathers. These interesting results coupled with the fact that parents did not differ in terms of sensitivity provide partial support to our second hypothesis and raise more questions than settle answers. What factors may explain higher levels of infants' responding to joint attention to maternal bids, when parents display the same mean amount of bids for attention as well as similar interactive sensitivity? And why do infants tend to exhibit more attempts to direct fathers' attention than mothers' attention?

We may speculate that the answer to the first question might reside on the possibility of mothers being more skillful in prolonging joint attention episodes, thus increasing the likelihood of infants engaging when mothers' bids are presented. This suggestion is consistent with previous 
findings that revealed that more competent partners (mothers vs. peers) may promote longer periods of infants' joint engagement (Bakeman \& Adamson, 1984). Furthermore, fathers may spend less time playing with their infant making them less proficient in engaging him/her in joint attention episodes. This, in turn, may push the infant to adopt a more active role in the interaction, which may also explain why there is a tendency for infants to show more initiating joint attention behaviors. There is evidence that sometimes father-child interactions are more demanding but that is what might fuel development itself. This is the case for language development (Lamb, 2010) as well as emotion regulation (Flanders et al., 2010). This might also be true for joint attention. Regarding the second question, its answer might be linked to the fact that fathers were found to adopt a less intrusive style than mothers while interacting with their infants. Adult intrusiveness has been suggested to negatively interfere with the infants’ agenda during triadic interactions involving the dyad and a toy, preventing them from spontaneously initiating joint engagement (Gaffan et al., 2010). By being less intrusive, fathers in our sample might have fostered their infants’ initiative and encouraged them to perform a more active role during toy play. Indeed, it is suggested that sensitive and non-intrusive care may increase infants’ likelihood to spontaneously establish joint engagement with a social partner (Hobson et al., 2004). Despite their attempts to engage infants in joint attention episodes, fathers can be sensitive enough to perceive when infants are not enjoying the current toy or object, and let infants play what they like the most. On the other hand, infants' own characteristics may also be determinative to explain their tendency for directing adult's attention. Osório and colleagues' (2011) findings suggest that expression of negative emotionality may negatively influence infant's attentional capabilities, especially initiating joint attention behaviours, preventing them from properly mobilizing these skills in order to explore the surrounding environment. It would be interesting to investigate whether infants' propensity to initiate more joint attention with fathers was related to their expression of negative emotionality. 
Some limitations of this study ought to be mentioned. First, the homogeneity of our sample in terms of families' social and cultural background may limit the generalization of these results to economically disadvantaged samples. Second, and due to restrictions in the design of the larger longitudinal study, of which the present report is a part, infant's assessments with their mothers always preceded infant-father interactions (which occurred about a fortnight later). An additional limitation refers to the duration of joint attention episodes, one aspect of great importance that would give our findings further support. Unfortunately, we could not reliably code this variable in our joint attention interactions, due to the camera angle at some points of the interaction, which prevented us from being sure of the infant's direction of gaze. The duration of joint attention episodes should, however, be considered in future research in order to clarify the father's contribution to infant joint attention. Additionally, we did not also gather information about the specific role each parent had in their infant's caregiving, as well as how much time they spent with their infant, especially playing with them. These valuable data would possibly contribute for the interpretation of our results. Finally, despite the interesting findings reported in this study, its preliminary and exploratory status does not allow for its generalization to typically developing infants. Further research should be carried out with larger samples so that conclusions about the father's role in the development of infant's joint attention can be drawn.

Nevertheless, our findings afford further evidence to the discussion of whether different indices of joint attention behaviors reflect common (e.g., Tomasello, 1995) rather than distinct sources of variance (Mundy, Card, \& Fox, 2000). In our study, responding to and initiating joint attention seemed to be related to distinct characteristics of parental interactive styles. The present investigation calls for bringing into the picture the fathers' contribution to joint attention development and, hereafter, regard them as potential social partners when assessing joint attention skills in infancy. Despite their young age, these 10-month-olds presented distinct patterns of joint attention behaviours according to their social partner and were already responsive to mother and 
father specific interactive style. Our findings strengthen the idea that parent-infant relationship contributes to early joint attention behaviours and by exploring its specificities individual differences in joint attention skills could be explained.

Finally, future research should take into account other qualitative specificities of father-infant interaction, already investigated in mother-infant dyads, such as parent scaffolding (Vaughan et al., 2003) and attachment security (Meins et al., 2011). Taking into account infant characteristics like temperament and emotion regulation, and how these might impact differentially on the development of joint attentional skills in infancy with different social partners could also be a fruitful research avenue.

\section{References}

Bakeman, R. \& Adamson, L. B. (1984). Coordinating attention to people and objects in motherinfant and peer-infant interaction. Child Development, 55(4), 1278-1289. doi: 10.2307/1129997

Belsky, J. (1979). Mother-father-infant interaction: A naturalistic observational study. Developmental Psychology, 15(6), 601-607. doi: 10.1037/0012-1649.15.6.601

Berlin, L. J., Cassidy, J., \& Appleyard, K. (2008). The influence of early attachments on other relationships. In J. Cassidy \& P. R. Shaver (Eds.), Handbook of Attachment: Theory, research, and clinical applications ( $2^{\text {nd }}$ ed., pp. 333-347). New York, NY: Guilford.

Bigelow, A. E., MacLean, K., Proctor, J., Myatt, T., Gillis, R., \& Power, M. (2010). Maternal sensitivity throughout infancy: Continuity and relation to attachment security. Infant Behavior \& Development, 33(1), 50-60. doi: 10.1016/j.infbeh.2009.10.009

Biringen, Z., Robinson, J. L., \& Emde, R. N. (1998). The emotional availability scales (3rd ed.). Unpublished manual: Colorado State University. 
Cabrera, N. J., Shannon, J. D., \& Tamis-LeMonda, C. (2007). Fathers’ influence on their children’s cognitive and emotional development: From toddlers to pre-K. Applied Development Science, 11(4), 208-213. doi: 10.1080/10888690701762100

Cabrera, N. J., Tamis-LeMonda, C. S., Bradley, R. H., Hofferth, S., \& Lamb, M. E. (2000). Fatherhood in the twenty-first century. Child Development, 71(1), 127-136. doi: 10.1111/14678624.00126

Carpenter, M., Nagell, K., \& Tomasello, M. (1998). Social cognition, joint attention, and communicative competence from 9 to 15 months of age. Monographs of the Society for Research in Child Development, 63(4), i+iii+v-vi+1-174. doi: 10.2307/1166214

Dawson, G., Toth, K., Abbott, R., Osterling, J., Munson, J., Estes, A., et al. (2004). Early social attention impairments in autism: Social orienting, joint attention, and attention to distress. Developmental Psychology, 40(2), 271-283. doi: 10.1037/0012-1649.40.2.271

Flanders, J. L., Simard, M., Paquette, D., Parent, S., Vitaro, F., Pihl, R. O., \& Séguin, J. R. (2010). Rough-and-Tumble play and the development of physical aggression and emotion regulation: A five-year follow-up study. Journal of Family Violence, 25(4), 357-367. doi: 10.1007/s10896009-9297-5

Gaffan, E. A., Martins, C., Healy, S., \& Murray, L. (2010). Early social experience and individual differences in infants’ joint attention. Social Development, 19(2), 369-393. doi: 10.1111/j.14679507.2008.00533.x

Grossmann, K., Grossmann, K. E., Kindler, H., \& Zimmermann, P. (2008). A wider view of attachment and exploration: The influence of mothers and fathers on the development of psychological security from infancy to young adulthood. In J. Cassidy \& P. R. Shaver (Eds.), Handbook of Attachment: Theory, research, and clinical applications (2 ${ }^{\text {nd }}$ ed., pp. 857-879). New York, NY: Guilford. 
Hobson, R. P., Patrick, M. P. H., Crandell, L. E., Pérez, R. M. G., \& Lee, A. (2004). Maternal sensitivity and infant triadic communication. Journal of Child Psychology and Psychiatry, 45(3), 470-480. doi: 10.1111/j.1469-7610.2004.00238.x

Howell, D. C. (2010). Statistical Methods for Psychology (7 $7^{\mathrm{a}}$ Ed). Belmont: Wadsworth.

Hsu, K. (1996). Joint attention in a father-child-mother triad: A Chinese-American case study. Issues in Applied Linguistics, 7(1), 77-90.

Lamb, M. E. (1975). Fathers: Forgotten contributors to child development. Human Development, 18(4), 245-266. doi: 10.1159/000271493.

Lamb, M. E. (2010). How do fathers influence children's development? Let me count the ways. In M. E. Lamb (Ed.), The role of the father in child development (5th ed., pp. 1-26). New Jersey: John Wiley \& Sons.

Lamb, M. E. \& Lewis, C. (2010). The development and significance of father-child relationships in two-parent families. In M. E. Lamb (Ed.), The role of the father in child development (5th ed., pp. 94-153). New Jersey: John Wiley \& Sons.

Lamb, M. E. \& Tamis-LeMonda, C. S. (2004). The role of the father: An introduction. In M. E. Lamb (Ed.), The role of the father in child development ( $4^{\text {th }}$ ed., pp. 1-31). New York: Wiley. Retrieved from http://media.wiley.com/product_data/excerpt/14/04712316/0471231614.pdf

Legerstee, M., Markova, G., \& Fisher, T. (2007). The role of maternal affect attunement in dyadic and triadic communication. Infant Behavior \& Development, 30(2), 296-306. doi: 10.1016/j.infbeh.2006.10.003

Martins, C. (2003). The emergence of secondary intersubjectivity: Predictors and sequeale in infants of well and depressed mothers. Unpublished doctoral dissertation. Reading, United Kingdom: University of Reading. 
Martins, E. C., Soares, I., Martins, C., Tereno, S., \& Osório, A. (2012). Can we identify emotion over-regulation in infancy? Associations with avoidant attachment, dyadic emotional interaction and temperament. Infant and Child Development, 21(6), 579-595. doi: 10.1002/icd.1760

Mateus, V., Martins, C., Osório, A., Martins, E. C., \& Soares, I. (2012). Joint attention at 10 months of age in infant-mother dyads: Contrasting free toy-play with semi-structured toy-play. Infant Behavior \& Development, http://dx.doi.org/10.1016/j.infbeh.2012.09.001

Meins, E., Fernyhough, C., Arnott, B., Vottorini, L., Turner, M., Leekam, S. R., \& Parkinson, K. (2011). Individual differences in infants’ joint attention behaviors with mother and a new social partner. Infancy, 16(6), 587-610. doi: 10.1111/j.1532-7078.2010.00065.x

Monteiro, L., Veríssimo, M., Vaughn, B. E., Santos, A. J., Torres, N., \& Fernandes, M. (2010). The organization of children's secure base behaviour in two-parent Portuguese families and father's participation in child-related activities. European Journal of Developmental Psychology, 7 (5), 545-560. doi: 10.1080/17405620902823855

Mundy, P., Block, J., Delgado, C., Pomares, Y., Vaughan Van Hecke, A. V., \& Parlade, V. M. (2007). Individual differences in the development of joint attention in infancy. Child Development, 78(3), 938-954. doi: 10.1111/j.1467-8624.2007.01042.x

Mundy, P., Card, J., \& Fox, N. (2000). EEG correlates of the development of infant joint attention skills. Developmental Psychobiology, 36(4), 325-338. doi: 10.1002/(SICI)10982302(200005)36:4<325::AID-DEV7>3.0.CO;2-F

Mundy, P., Delgado, C., Block, J., Venezia, M., Hogan, A., \& Seibert, J. (2003). A manual for the Abridged Early Social Communication Scales (ESCS). Retrieved from http://www.ucdmc.ucdavis.edu/mindinstitute/ourteam/faculty_staff/ESCS.pdf

Mundy, P., \& Sigman, M. (2006). Joint attention, social competence and developmental psychopathology. In D. Cicchetti and D. Cohen (Eds.), Developmental psychopathology, second 
Edition, volume one: Theory and methods (pp. 293-32), Hoboken, N. J.: Wiley. Retrieved from http://www.ucdmc.ucdavis.edu/mindinstitute/ourteam/faculty_staff/JASocialCompetence.pdf

Nelson, P. B., Adamson, L. B., \& Bakeman, R. (2008). Toddlers’ joint engagement experience facilitates preschoolers' acquisition of theory of mind. Developmental Science, 11(6), 847-852. doi: 10.1111/j.1467-7687.2008.00733.x

Osório, A., Martins, C., Meins, E., Martins, E. C., \& Soares, I. (2011). Individual and relational contributions to parallel and joint attention in infancy. Infant Behavior \& Development, 34(4), 515-524. doi: 10.1016/j.infbeh.2011.07.005

Pancsofar, N., Vernon-Feagans, L., \& The Family Life Project Investigators (2010). Fathers’ early contributions to children's language development in families from low-income rural communities. Early Childhood Research Quarterly, 25(4), 450-463. doi: 10.1016/j.ecresq.2010.02.001

Rutherford, M. D. \& Przednowek, M. (2012). Fathers show modifications of infant-directed action similar to that of mothers. Journal of Experimental Child Psychology, 111(3), 367-378. doi: 10.1016/j.jecp.2011.10.012

Sheinkopf, S., Mundy, P., Claussen, A., \& Willoughby, J. (2004). Infant joint attention skill and preschool behavioral outcomes in at-risk children. Development and Psychopathology, 16(2), 273-291. doi: 10.1017/S0954579404044517

Tamis-LeMonda, C. S., Shannon, J. D., Cabrera, N. J., \& Lamb, M. E. (2004). Fathers and mothers at play with their 2- and 3-year-olds: Contributions to language and cognitive development. Child Development, 75(6), 1806-1820. doi: 10.1111/j.1467-8624.2004.00818.x

Tomasello, M. (1995). Joint attention as social cognition. In C. Moore, \& P. Dunham (Eds.), Joint attention: Its origins and role in development (pp. 103-130). Hillsdale, NJ: Erlbaum.

Toth, K., Munson, J., Meltzoff, A., \& Dawson, G. (2006). Early predictors of communication development in young children with autism spectrum disorder: Joint attention, imitation, and toy 
play. Journal of Autism and Developmental Disorders, 36(8), 993-1005. doi: 10.1007/s10803006-0137-7

Vaughan Van Hecke, A., Mundy, P. C., Acra, C. F., Block, J. J., Delgado, C. E. F., Parlade, M. V., et al. (2007). Infant joint attention, temperament, and social competence in preschool children. Child Development, 78(1), 53-69. doi: 10.1111/j.1467-8624.2007.00985.x

Vaughan, A., Mundy, P., Block, J., Burnette, C., Delgado, C., Gomez, Y., et al. (2003). Child, caregiver, and temperament contributions to infant joint attention. Infancy, 4(4), 603-616. doi: 10.1207/S15327078IN0404_11 
Table 1

Mothers, Fathers, and Infants Joint Attention Behaviors during Semi-Structured Toy Play

\begin{tabular}{lccccc}
\hline & \multicolumn{2}{c}{ Mother } & \multicolumn{2}{c}{ Father } \\
& Min-Max & $M(S D)$ & Min-Max & $M(S D)$ & Statistics \\
\hline Parent $^{a}$ & & & & & \\
Bids for joint attention & $62-246$ & $126.67(39.42)$ & $49-223$ & $117.52(40.87)$ & $t(51)=1.48$ \\
\hline Infant $^{b}$ & & & & & \\
Responding to joint attention & $0-.07$ & $.01(.02)$ & $0-.06$ & $.01(.02)$ & $Z=-2.16^{*}$ \\
Initiating joint attention & $0-8$ & $1.06(1.70)$ & $0-11$ & $1.63(2.39)$ & $Z=-1.90^{+}$ \\
\hline
\end{tabular}

Note: ${ }^{a}$ t-test for paired samples; ${ }^{b}$ Wilcoxon Sign Test

${ }^{*} p<.05 ;{ }^{+} p<.10$ 
Table 2

Mothers' and Fathers' Interactive Style during Daily Interaction

\begin{tabular}{lccccc}
\hline \hline & \multicolumn{2}{c}{ Mother } & \multicolumn{2}{c}{ Father } \\
& Min-Max & $M(S D)$ & Min-Max & $M(S D)$ & Statistics \\
\hline \hline & & & & & \\
Sensitivity & $2-7$ & $5.17(1.29)$ & $3-8$ & $5.46(1.04)$ & $Z=-1.05$ \\
Non-Intrusiveness & $1-5$ & $4.15(.92)$ & $2-5$ & $4.58(.70)$ & $Z=-3.09^{* *}$ \\
\hline$* * p<.01$ & & & & &
\end{tabular}

